\title{
Simultaneous Determination of Water Retention Curve and Unsaturated Hydraulic Conductivity of Substrates Using a Steady-state Laboratory Method
}

\author{
Paraskevi A. Londra \\ Agricultural University of Athens, Department of Natural Resources \\ Management and Agricultural Engineering, Laboratory of Agricultural \\ Hydraulics, 75 Iera Odos, Athens 11855, Greece
}

Additional index words. peat, coir, perlite, steady-state profiles, hydraulic properties

\begin{abstract}
For effective irrigation and fertilization management, the knowledge of substrate hydraulic properties is essential. In this study, a steady-state laboratory method was used to determine simultaneously the water retention curve, $\theta(h)$, and unsaturated hydraulic conductivity as a function of volumetric water content, $K(\theta)$, and water pressure head, $K(h)$, of five substrates used widely in horticulture. The substrates examined were pure peat, $75 / 25$ peat/perlite, $50 / 50$ peat/perlite, $50 / 50 \mathrm{coir} /$ perlite, and pure perlite. The experimental retention curve results showed that in the case of peat and its mixtures with perlite, there is a hysteresis between drying and wetting branches of the retention curve. Whereas in the case of coir/perlite and perlite, the phenomenon of hysteresis was less pronounced. The increase of perlite proportion in the peat/perlite mixtures led to a decrease of total porosity and water-holding capacity and an increase of air space. Study of the $K(\theta)$ and $K(h)$ experimental data showed that the hysteresis phenomenon of $K(\theta)$ was negligible compared with the $K(h)$ data for all substrates examined. Within a narrow range of water pressure head $\left(0\right.$ to $\left.-70 \mathrm{~cm} \mathrm{H}_{2} \mathrm{O}\right)$ that occurs between two successive irrigations, a sharp decrease of the unsaturated hydraulic conductivity was observed. The comparison of the $K(\theta)$ experimental data between the peat-based substrate mixtures and the coir-based substrate mixture showed that for water contents lower than $0.40 \mathrm{~m}^{3} \cdot \mathrm{m}^{-3}$, the hydraulic conductivity of the $50 / 50$ coir/perlite mixture was greater. The comparison between experimental water retention curves and predictions using Brooks-Corey and van Genuchten models showed a high correlation $\left(0.992 \leq \boldsymbol{R}^{2} \leq\right.$ 1) for both models for all substrates examined. On the other hand, in the case of unsaturated hydraulic conductivity, the comparison showed a relatively good correlation $\left(0.951 \leq R^{2} \leq 0.981\right)$ for the van Genuchten-Mualem model for all substrates used except perlite and a significant deviation $\left(0.436 \leq R^{2} \leq 0.872\right)$ for the Brooks-Corey model for all substrates used.
\end{abstract}

Crop transpiration needs depend not only on the existing environmental conditions, but also on the rate of water supply to the roots. Both water supply to plants and substrate aeration are estimated from the substrate hydraulic properties (Da Silva et al., 1993; De Boodt and Verdonck, 1972; Heiskanen, 1993a, 1993b, 1993c; Puustjäarvi, 1977). Therefore, the knowledge of both hydraulic properties, water retention function $\theta(h)$ and unsaturated hydraulic conductivity as a function of volumetric water content, $K(\theta)$, or water pressure head, $K(h)$, is of vital importance for effective irrigation and fertilization management. The knowledge of the unsaturated hydraulic conductivity is especially essential in substrates where significant changes in $\theta$ and $K$ occur in a narrow range in pressure head, which practically happen between irrigations (Da Silva,

Received for publication 13 Apr. 2010. Accepted for publication 23 May 2010.

e-mailv.londra@aua.gr. the unsaturated hydraulic conductivity in different substrates does not facilitate the creation of a standard mathematical form for its determination.

Although the soil water retention function can easily be determined by measuring water contents at different pressure heads, the unsaturated hydraulic conductivity measurement is often laborious, time-consuming, and may require expensive equipment. To overcome these difficulties, statistical pore-size distribution models have been proposed to predict hydraulic conductivity from the more easily measured water retention data and the measured value of saturated hydraulic conductivity $K_{s}$ (Burdine, 1953; Childs and Collis George, 1950; Mualem, 1976). Furthermore, the introduction of continuous analytical functions to the retention curve combined with capillary theories leads to different closed-form analytical models describing soil hydraulic properties (Brooks and Corey, 1964; van Genuchten, 1980). Unfortunately, in some cases, the calculated $K(\theta)$ values using the retention curve data and the saturated hydraulic conductivity may deviate significantly from the actual $K(\theta)$ values (Poulovassilis et al., 1988; Talsma, 1985; Valiantzas and Sassalou, 1991).

The principal objective of this study was to determine simultaneously both hydraulic properties, $\theta(h)$ and $K(\theta), K(h)$, of five substrates used widely in horticulture using a steady-state laboratory method. Contrary to current research (Bilderback et al., 1982; Da Silva, 1991; Fonteno et al., 1981; Milks et al., 1989; Wallach et al., 1992b), the method studied in this article enables to measure directly and simultaneously both basic hydraulic properties, in the same substrate sample, in a range of water pressure head that occurs between irrigations $(0$ to $-70 \mathrm{~cm})$. Therefore, the use of an individual sample in this method not only simplifies the standard procedure used to date to define the hydraulic properties of the substrates and for a greater range of water pressure head between irrigations, but in addition has the advantage of defining these properties under the same conditions. The second main objective of this work was to compare the values of the hydraulic properties measured with the equivalent values predicted by the most popular closedform analytical hydraulic models of Brooks and Corey (1964) and van Genuchten (1980) and assess the validity of these models.

\section{Materials and Methods}

Theory. A sufficiently long column of a porous material, drying to a stationary water table, attains in its upper part a state of uniform water content $\theta$ and pressure head $h$ when subjected to infiltration at its upper end at a constant flow rate $q$ (Youngs, 1957). The flow rate $q$ can be calculated using Darcy's law as:

$$
q=-K\left(\frac{d H}{d z}\right)=-K\left(\frac{d h}{d z}+1\right)
$$
tivity as a function of water pressure head $K(h)$ for a narrow range of pressure head ( 0 to -25 $\mathrm{cm}$ ) applying different methods to different samples. Furthermore, the large variation of where $K$ is the unsaturated hydraulic conductivity, $H$ is the hydraulic head $(H=h+z)$, and 
$z$ is the elevation head relative to an arbitrary datum.

The flow rate $q$ of the upper uniform part of the porous material column equals the hydraulic conductivity $K$ because the gradient of the pressure head is zero. Below this uniform part of the column, the water content increases gradually and reaches the saturation value at the base of the column, whereas the pressure head decreases and becomes zero at the base of the column. By imposing the pressure head $h$ of the upper part of the column, at the base of the column, the uniform part can be extended to the whole length of the porous material column. Thus, a uniform steady-state water profile can be built up with water content $\theta$ at a pressure head $h$ sustained by the flow rate $q=K$ (Poulovassilis, 1970).

In this article, the simultaneous determination of $\theta(h)$ and $K(\theta), K(h)$ is based on a similar method referred by Poulovassilis (1970).

Calculation of hydraulic properties by closed-form hydraulic models. Brooks and Corey (1964) suggested the following analytical expression to describe the water retention curve $\theta(h)$ :

$$
\theta(h)=\left(\theta_{s}-\theta_{r}\right)\left(\frac{h_{v}}{h}\right)^{\lambda}+\theta_{r}
$$

where $\theta_{s}$ and $\theta_{r}$ are the saturated and residual values of the volumetric water content $\theta$, respectively, $h_{v}$ is the air-entry value of $h$, and $\lambda$ is the pore size distribution index.

The unsaturated hydraulic conductivity $K$ is related to the volumetric water content $\theta$ according to the following relationship:

$$
K(\theta)=K_{s}\left(\frac{\theta-\theta_{r}}{\theta_{s}-\theta_{r}}\right)^{p+2+2 / \lambda}
$$

where $K_{s}$ is the saturated hydraulic conductivity and $p$ is a soil-specific parameter that accounts for the tortuosity of the flow. The $p$ value used in the present study is the conventional value of 0.5 (Mualem, 1976).

van Genuchten (1980) described the water retention curve with the following expression:

$$
\theta(h)=\left(\theta_{s}-\theta_{r}\right)\left(\frac{1}{1+\alpha|h|^{n}}\right)^{m}+\theta_{r}
$$

where $a, m$, and $n$ are retention curve fitting parameters, $m=1-1 / n$ and $0<m<1$.

Combining Eq. [4] with the model developed by Mualem (1976), the unsaturated hydraulic conductivity $K(\theta)$ can be calculated by the following expression:

$$
\begin{aligned}
K(\theta)= & K_{s}\left(\frac{\theta-\theta_{r}}{\theta_{s}-\theta_{r}}\right)^{0.5} \\
& \times\left\{1-\left[1-\left(\frac{\theta-\theta_{r}}{\theta_{s}-\theta_{r}}\right)^{1 / m}\right]^{m}\right\}^{2}
\end{aligned}
$$

Substrates. Substrates are commonly used in the greenhouse industry because of their beneficial properties, e.g., they are lightweight, easily available, and consistent. Compared with soils, substrates have often better physical properties (e.g., higher air-filled porosity or water-holding capacity) depending on their substance, are well drained, and free from microorganisms and seeds. Substrates usually provide relatively low nutrient-holding capacity and for this reason, greenhouse crops require more frequent fertilization and nutritional management.

There are a number of substrates that can nations to make substrate mixes. The choice of a particular material is determined by its availability, cost, and physical properties.

In this study, the five substrates used were selected to cover the range of porous materials used in container plant production. All substrates were based on peat, coir, and floriculture perlite (Londra, 2001). The peat was Lithuanian sphagnum peatmoss. The coir was in compressed form with dimensions $20 \times 10 \times 5 \mathrm{~cm}$ and was a byproduct of coconut husk fiber treatment. The peat-based substrate mixtures were created with (on a volume basis): 1) 100\% Lithuanian sphagnum peat; 2) 75\% Lithuanian sphagnum peat and 25\% perlite; and 3) 50\% Lithuanian sphagnum peat and $50 \%$ perlite. The coirbased substrate mixture was created with (on a volume basis) $50 \%$ coir and $50 \%$ perlite. Furthermore, $100 \%$ perlite was used.

Experimental procedure. To determine simultaneously the water retention curve $\theta(h)$ and unsaturated hydraulic conductivity as a function of water content $K(\theta)$ and water pressure head $K(h)$ of the five substrates, a steady-state infiltration experiment was conducted in the laboratory. Five substrate columns of peat, $75 / 25$ peat/perlite, $50 / 50$ peat/ perlite, 50/50 coir/perlite, and perlite were used in an experimental arrangement that is described in Figure 1.

The experimental apparatus consisted of a transparent acrylic tube $60 \mathrm{~cm}$ high with an internal diameter of $7 \mathrm{~cm}$. Each tube was constructed from 24 individual rings $2.5 \mathrm{~cm}$ high, which were fixed together with special adhesive transparent tape. Holes were inserted be used either separately or in various combi-

in the middle height of 14 of the individual rings to position the porous capsules of mercury tensiometers as shown in Figure 1. For the experimental needs, five tubes were used, one for each substrate column. The substrate column rested on a tension porous plate (with air pressure entry value $180 \mathrm{~cm}$ of water) in contact with a reservoir of water $4 \mathrm{~cm}$ high with an internal diameter of $7 \mathrm{~cm}$ from the same matter of the tube attached to the lower

\begin{tabular}{|c|c|c|c|c|c|}
\hline \multirow[b]{2}{*}{ Particle size (mm) } & \multicolumn{5}{|c|}{ Particle size distribution $(\%$ by wt $)$} \\
\hline & Peat & $\begin{array}{c}75 / 25 \\
\text { peat/perlite }\end{array}$ & $\begin{array}{c}50 / 50 \\
\text { peat/perlite }\end{array}$ & $\begin{array}{c}50 / 50 \\
\text { coir/perlite }\end{array}$ & Perlite \\
\hline Greater than 8.000 & 7.65 & 5.97 & 4.51 & 0.00 & 0.00 \\
\hline $8.00-4.00$ & 17.44 & 17.77 & 13.75 & 4.87 & 5.83 \\
\hline $4.00-2.00$ & 16.56 & 34.40 & 31.93 & 27.50 & 42.69 \\
\hline $2.00-1.00$ & 17.64 & 15.07 & 21.85 & 25.89 & 30.45 \\
\hline $1.00-0.50$ & 19.08 & 12.57 & 11.22 & 19.29 & 8.67 \\
\hline $0.50-0.25$ & 11.49 & 6.51 & 7.18 & 12.79 & 2.22 \\
\hline $0.25-0.125$ & 5.74 & 3.43 & 3.94 & 5.26 & 1.41 \\
\hline $0.125-0.068$ & 2.86 & 2.23 & 2.72 & 2.20 & 3.37 \\
\hline Less than 0.068 & 1.54 & 2.06 & 2.90 & 2.20 & 5.37 \\
\hline
\end{tabular}

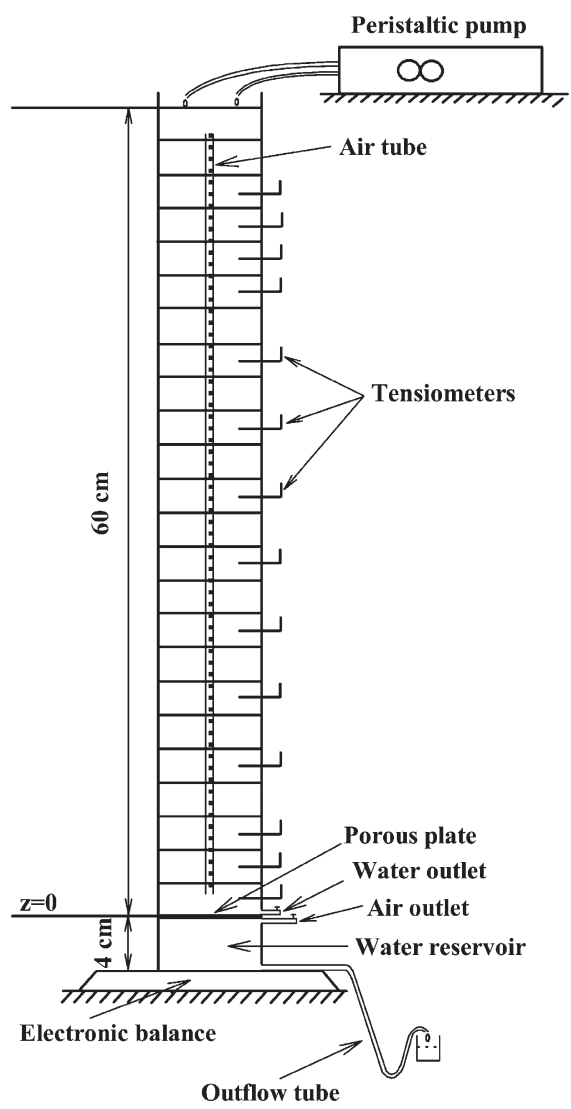

Fig. 1. Schematic presentation of the experimental apparatus.

Table 1. Particle size distribution of various substrates.

Table 2. Bulk density and saturated hydraulic conductivity of various substrates.

\begin{tabular}{lcc}
\hline Substrate & $\begin{array}{c}\text { Bulk density } \\
\left(\mathrm{g} \cdot \mathrm{cm}^{-3}\right)\end{array}$ & $\begin{array}{c}\text { Saturated hydraulic } \\
\text { conductivity }\left(\mathrm{cm} \cdot \mathrm{min}^{-1}\right)\end{array}$ \\
\hline Peat & 0.0815 & 1.32 \\
$75 / 25$ peat/perlite & 0.1003 & 3.54 \\
$50 / 50$ peat/perlite & 0.1159 & 7.13 \\
$50 / 50$ coir/perlite & 0.0939 & 11.07 \\
Perlite & 0.1039 & 8.76 \\
\hline
\end{tabular}



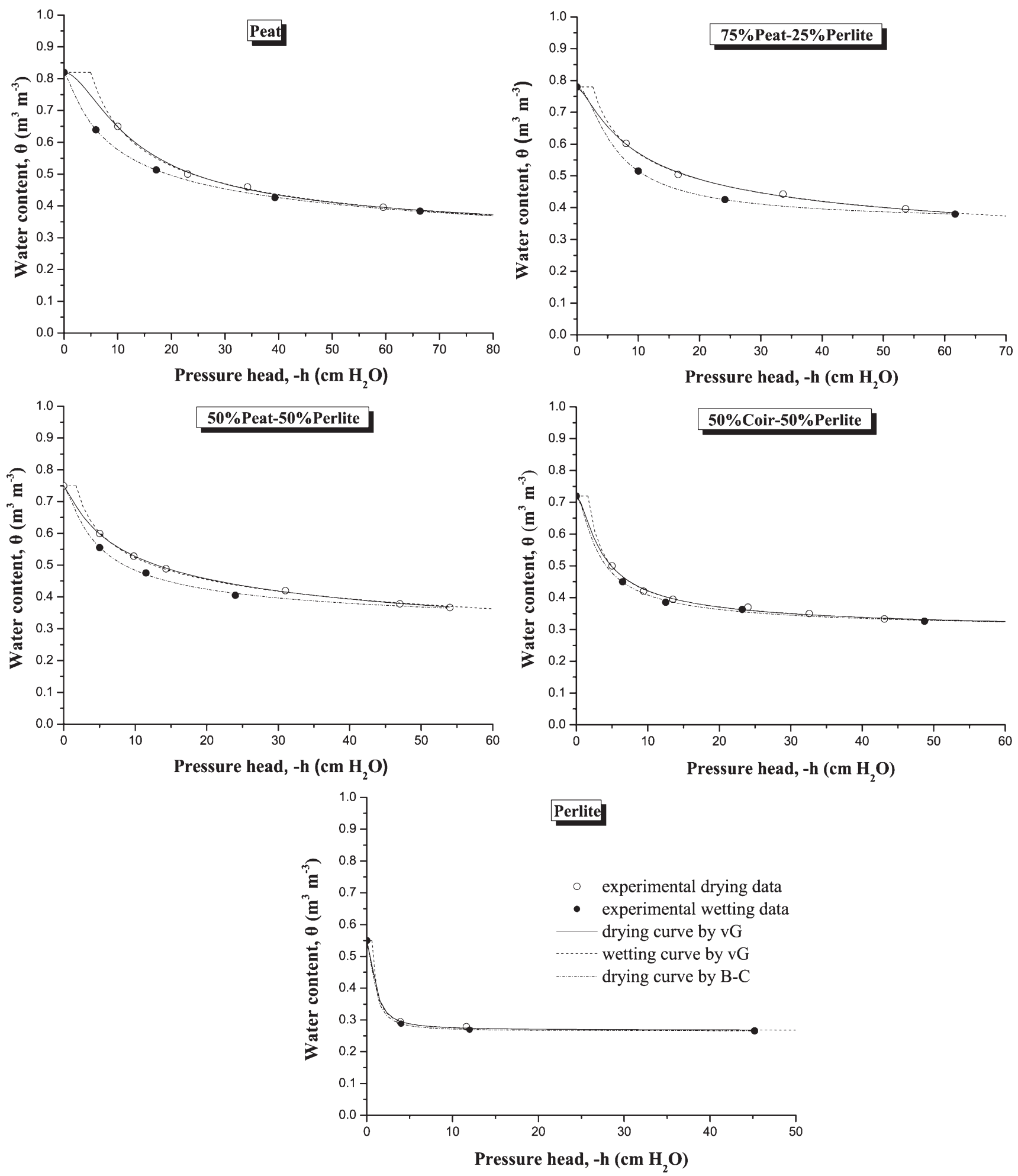

Fig. 2. Experimental and fitted by Brooks-Corey (B-C) and van Genuchten (vG) models of water retention curves during drying and wetting for various substrates.

end of the tube. The water reservoir had two outlets, one for the water outflow and the other for the outlet of possible entrapped air (Fig. 1). The substrate samples were uniformly wet before using. To achieve satisfactory packing of the substrate column, small amounts of substrate were gradually put in the tube with simultaneous vibration of the tube. Before placement of the substrate samples into the columns, filter paper was placed above the porous plate to contain and therefore prevent the fine organic material of the substrate from clogging the pores of the plate. Therefore, note that an air tube was centrally put in along each substrate column to remove the entrapped air from the substrate (Fig. 1). This tube was a stainless sieve with a $1-\mathrm{mm}$ screen. The saturation of the substrate columns was achieved by wetting them gradually from the lower end through the porous plate adding water under pressure by means of the water reservoir. At this stage, a $1 \%$ phenol solution was used during saturation to prevent the development of fungal infections throughout the duration of the experiment. The substrate columns were saturated for $\approx 3 \mathrm{~d}$ and then they were allowed to dry by opening the outflow tube at a distance of $150 \mathrm{~cm}$ from the substrate column surface. After that, the substrate columns were subjected to a wetting procedure (in the same manner as described previously) and then were allowed to dry by applying various constant flow rates $q_{i}$ at their surface. The 
applied flow rates were lower than the saturated hydraulic conductivity $K_{s}$ of the substrates $\left(K_{s}>q_{1}>q_{2}>\ldots q_{n}\right)$.

In the drying procedure, under constant flow rate $q_{i}$, the pressure head $h_{i}$ of the upper uniform part of the substrate column was being imposed by means of the tension plate of the column base (by lowering gradually the level of the water outflow tube); therefore, the uniform part was being extended to the whole length of the substrate column. So, a uniform steady-state water profile can be

Table 3. Fitted Brooks-Corey (B-C) and van Genuchten (vG) retention curve parameters.

\begin{tabular}{llccccr}
\hline & & & $75 / 25$ & $50 / 50$ & $50 / 50$ & \\
& & Peat & peat/perlite & peat/perlite & coir/perlite & Perlite \\
\hline B-C drying & $h_{v}$ & 4.967 & 2.580 & 1.726 & 1.616 & 0.608 \\
& $\lambda$ & 0.453 & 0.257 & 0.205 & 0.616 & 1.226 \\
& $\theta_{r}$ & 0.191 & 0.070 & 0.000 & 0.277 & 0.267 \\
vG drying & $R^{2}$ & 0.998 & 0.997 & 0.998 & 0.992 & 0.995 \\
& $\alpha$ & 0.120 & 0.234 & 0.387 & 0.487 & 1.444 \\
& $n$ & 1.813 & 1.438 & 1.253 & 1.724 & 2.320 \\
vG wetting & $\theta_{r}$ & 0.289 & 0.207 & 0.041 & 0.288 & 0.267 \\
& $R^{2}$ & 0.999 & 0.999 & 0.999 & 0.998 & 0.999 \\
& $\alpha$ & 0.326 & 0.255 & 0.489 & 0.566 & 1.504 \\
& $n$ & 1.340 & 1.931 & 1.483 & 1.744 & 2.399 \\
& $\theta_{r}$ & 0.147 & 0.347 & 0.265 & 0.293 & 0.265 \\
& $R^{2}$ & 0.999 & 1.000 & 0.999 & 0.999 & 1.000 \\
\hline
\end{tabular}

built up with a water content $\theta_{i}$ at a pressure head $h_{i}$ sustained by the flow rate $q_{i}=K_{i}$. In the wetting procedure, similar treatments were followed raising gradually the level of the water outflow tube until a uniform steady-state water profile was achieved. The time needed to reach stable flow ranged from 1 to $5 \mathrm{~d}$ for big to low capillary pressures, respectively.

During the experimental procedure, the apparatus was mounted on an electronic balance connected to a PC so that the water content could be deduced at all times from the indicated total mass. Consequently, the water retention curve was directly measured by means of the values of tensiometers sensors and substrate column weights.

The constant flow rates were achieved by using a peristaltic pump. During the experimental procedure, the applied constant flow rates at the substrate column surfaces ranged from 3.85 to $0.0007 \mathrm{~cm}^{3} \cdot \mathrm{min}^{-1}$. The flow rate was uniformly distributed through the two
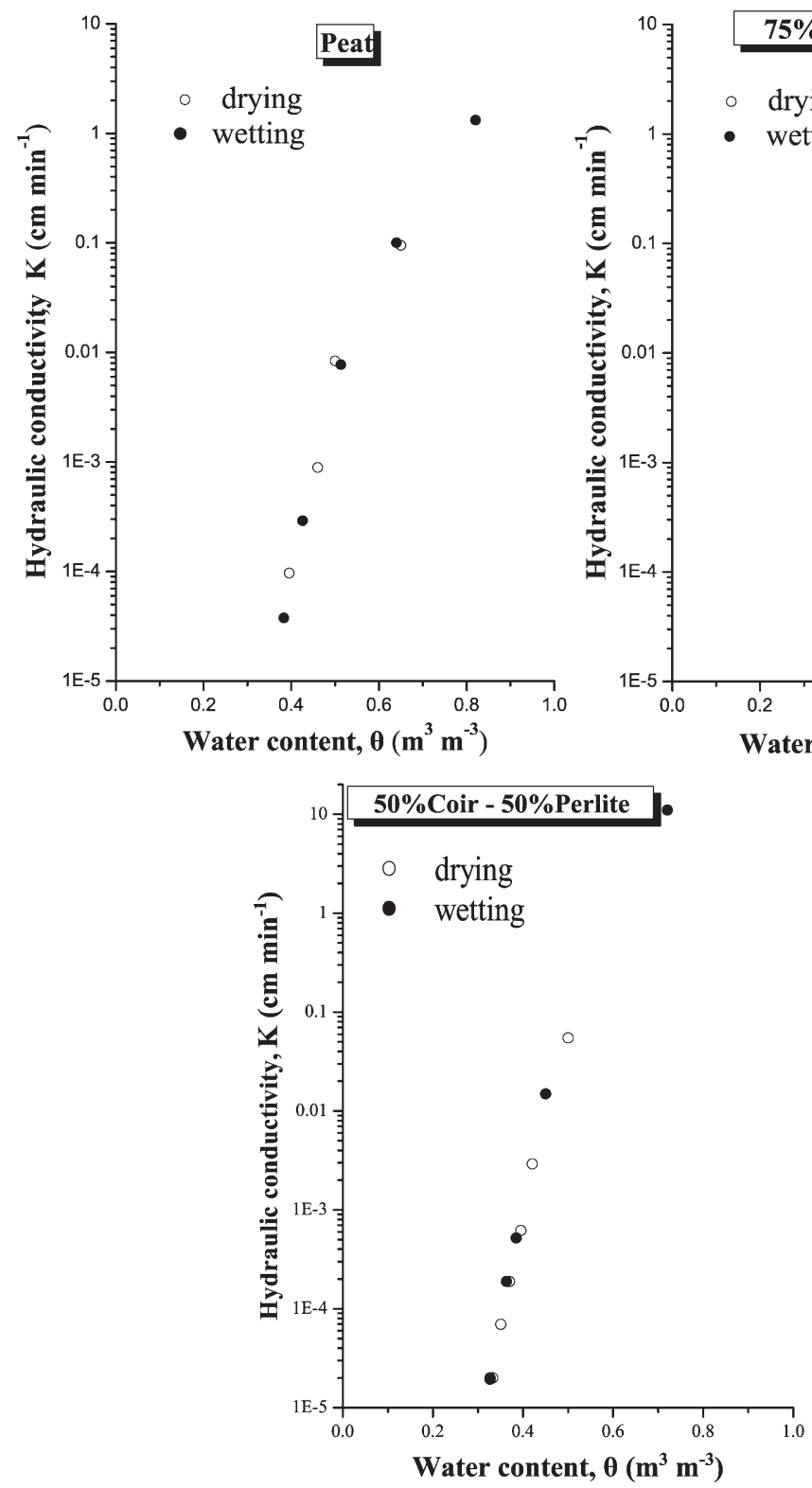
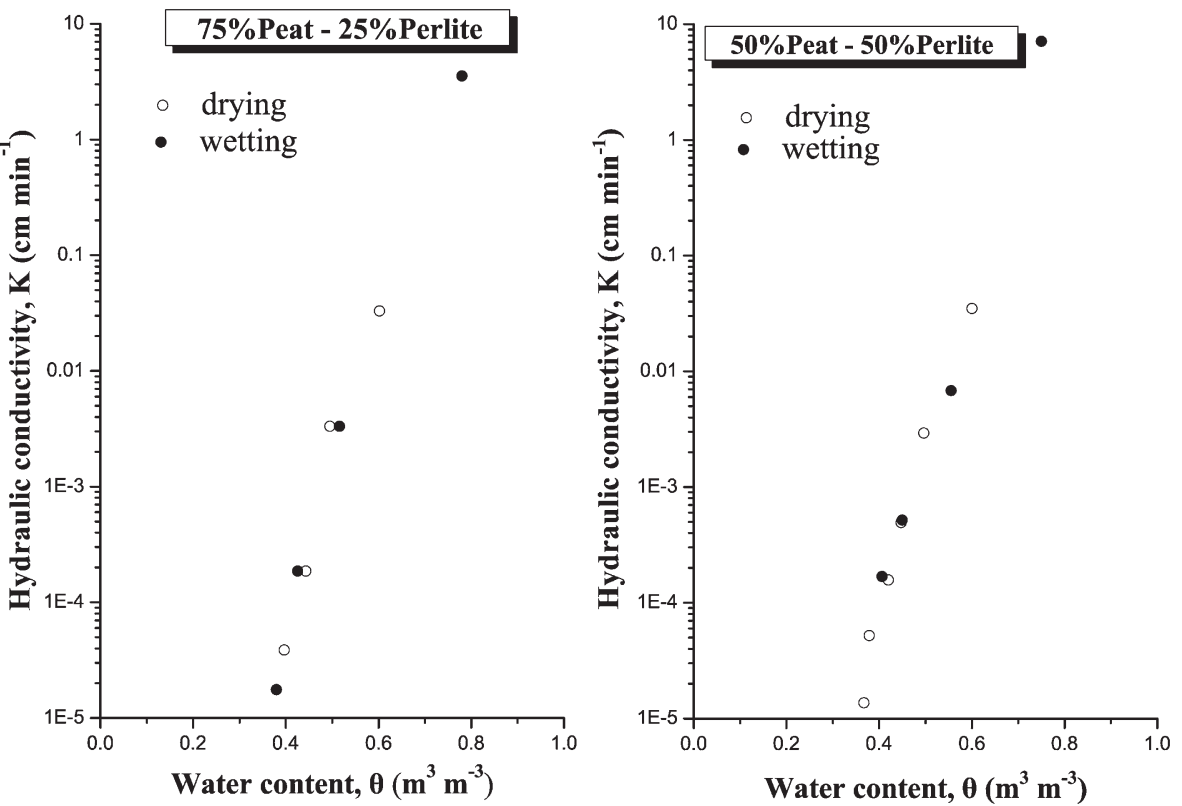

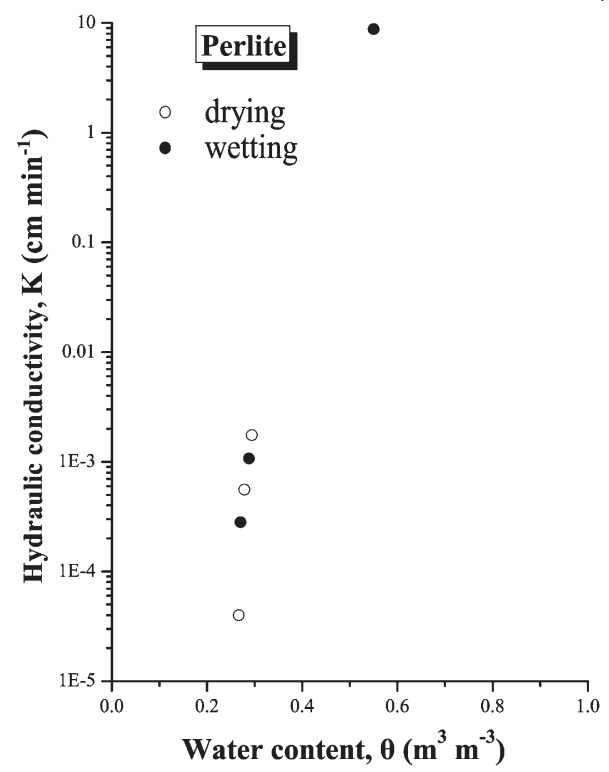

Fig. 3. Experimental hydraulic conductivity as a function of water content during drying and wetting for various substrates. 

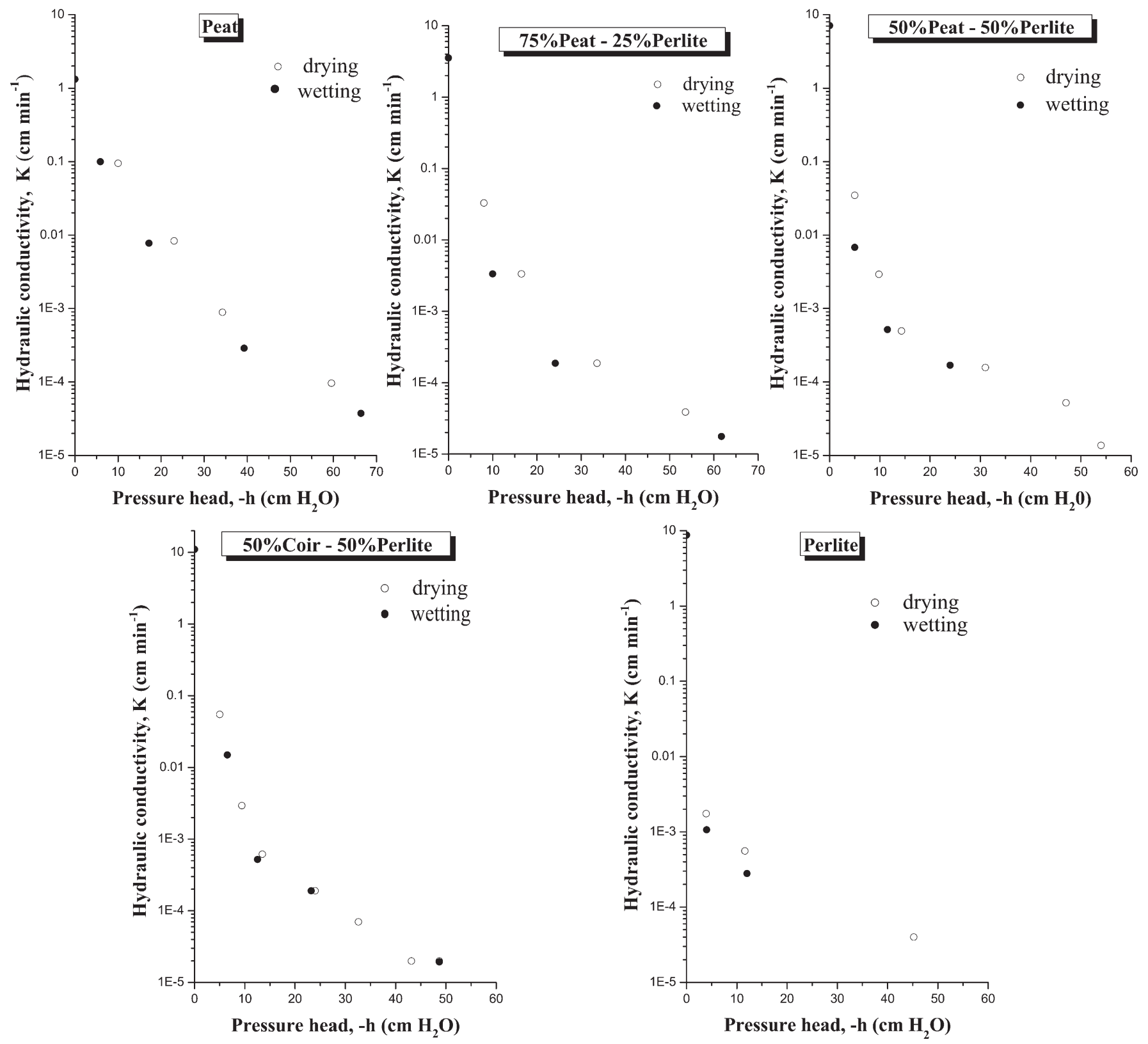

Fig. 4. Experimental hydraulic conductivity as a function of pressure head during drying and wetting for various substrates.

tubes of the peristaltic pump from the substrate column surface.

The pressure head values at different heights (14 points) of the substrate column were measured by mercury tensiometers.

The saturated hydraulic conductivity, $K_{s}$, was determined in the same arrangement of the column by the constant head method releasing water through the water outlet located above the porous plate (Fig. 1) before the start of the experimental procedure. Each sample was subjected to a wetting-drying cycle before the measurement.

So, the method described gave us the opportunity to directly and simultaneously measure both hydraulic properties $\theta(h)$ and $K(\theta), K(h)$ under the same conditions using only one substrate sample.

Also, the particle size distribution of the substrates used was determined using sieves with 0.068-, 0.125-, 0.25-, 0.50-, 1.00-, 2.00-,

Table 4. Coefficient of determination $R^{2}$ and root mean squared errors (RMSE) of the Brooks-Corey (B-C) and van Genuchten-Mualem (vG-M) $K(\theta)$ fitted curves.

\begin{tabular}{lcccc}
\hline & \multicolumn{2}{c}{ B-C } & \multicolumn{2}{c}{ vG-M } \\
\cline { 2 - 5 } Substrate & $R^{2}$ & RMSE & $R^{2}$ & RMSE \\
\hline Peat & 0.872 & 0.574 & 0.981 & 0.221 \\
$75 / 25$ peat $/$ perlite & 0.612 & 1.146 & 0.954 & 0.396 \\
$50 / 50$ peat/perlite & 0.436 & 1.360 & 0.951 & 0.400 \\
$50 / 50$ coir/perlite & 0.871 & 0.663 & 0.981 & 0.252 \\
Perlite & 0.760 & 0.917 & 0.57 & 1.227 \\
\hline
\end{tabular}

4.00-, and 8.00-mm screen sizes on a mechanical shaker for $3 \mathrm{~min}$ at 30 shakes per minute.

\section{Results and Discussion}

The substrate particle size distribution has an important role in the formation of the substrate porosity and consequently in the shaping of both hydraulic properties, water retention curve and hydraulic conductivity. The particle size distribution of the substrates studied is given in Table 1.

In Table 2, the values of bulk density and saturated hydraulic conductivity of the substrates used are presented. As shown, all the substrates examined have low values of bulk density and high values of saturated hydraulic conductivity. 
Figure 2 depicts the experimental drying and wetting data of the retention curve of the substrates used. As shown, in the case of peat and its mixtures with perlite, there is a hysteresis between the drying and wetting branches of the retention curve. The hysteresis phenomenon may be influenced by peat hydrophobicity (Beardsell and Nichols, 1982; Naasz et al., 2008). Whereas in the case of coir/perlite and perlite, the phenomenon of hysteresis was less pronounced.

Also, it is obvious that the increase in perlite proportion in the peat/perlite mixtures led to the decrease of total porosity and waterholding capacity and to the increase of air space. Specifically, during drying, peat exhibited the higher total porosity of $82 \%$ (water content in the $0-\mathrm{cm}$ pressure head) among its mixtures with perlite, an air space of $17 \%$ (air content in a $-10-\mathrm{cm}$ pressure head), and easily available water $24 \%$ (water content in a region of -10 - to $-50-\mathrm{cm}$ pressure head), concepts introduced by De Boodt and Verdonck (1972).The substrates 75/25 peat/perlite and $50 / 50$ peat/perlite exhibited total porosity of $78 \%$ and $75 \%$, air space of $21 \%$ and $22.5 \%$, and easily available water of $17 \%$ and $15 \%$, respectively. The perlite behavior is explained by its particle size distribution (Table 1). This substrate has the highest percentage of coarse particles $(42.69 \%$ and $30.45 \%$ between 2 and $4 \mathrm{~mm}$ and 1 and $2 \mathrm{~mm}$, respectively) than the other substrates used. So, the addition of perlite in the mixtures contributes to the increased amount of large pores. Note that the knowledge of the effect of perlite in various substrate mixtures is very important mainly when we have to choose correct components of substrate mixes according to crop needs in water content and air porosity. On the other hand, the substrates 50/50 coir/perlite and the pure perlite exhibited total porosity at $72 \%$ and $55 \%$, air space at $30 \%$ and $27.5 \%$, and easily available water at $9 \%$ and $1 \%$, respectively. In the case of wetting, the percentages of air space and easily available water are higher and lower, respectively, than those in drying (Fig. 2).

The information that these substrate water retention curves provide for the range of pressure heads from 0 to $-70 \mathrm{~cm} \mathrm{H}_{2} \mathrm{O}$ is of vital importance to plant growth. As mentioned by De Boodt and Verdonck (1972), the water content between a -10 - and $-100-\mathrm{cm}$ pressure head is important to ornamental plant growth in substrates. Water retention in pressure head larger than $-100 \mathrm{~cm}$ decreases plant growth and less than $-10 \mathrm{~cm}$ produces inadequate substrate aeration.

In the same figure (Fig. 2), a comparison between the experimental water retention
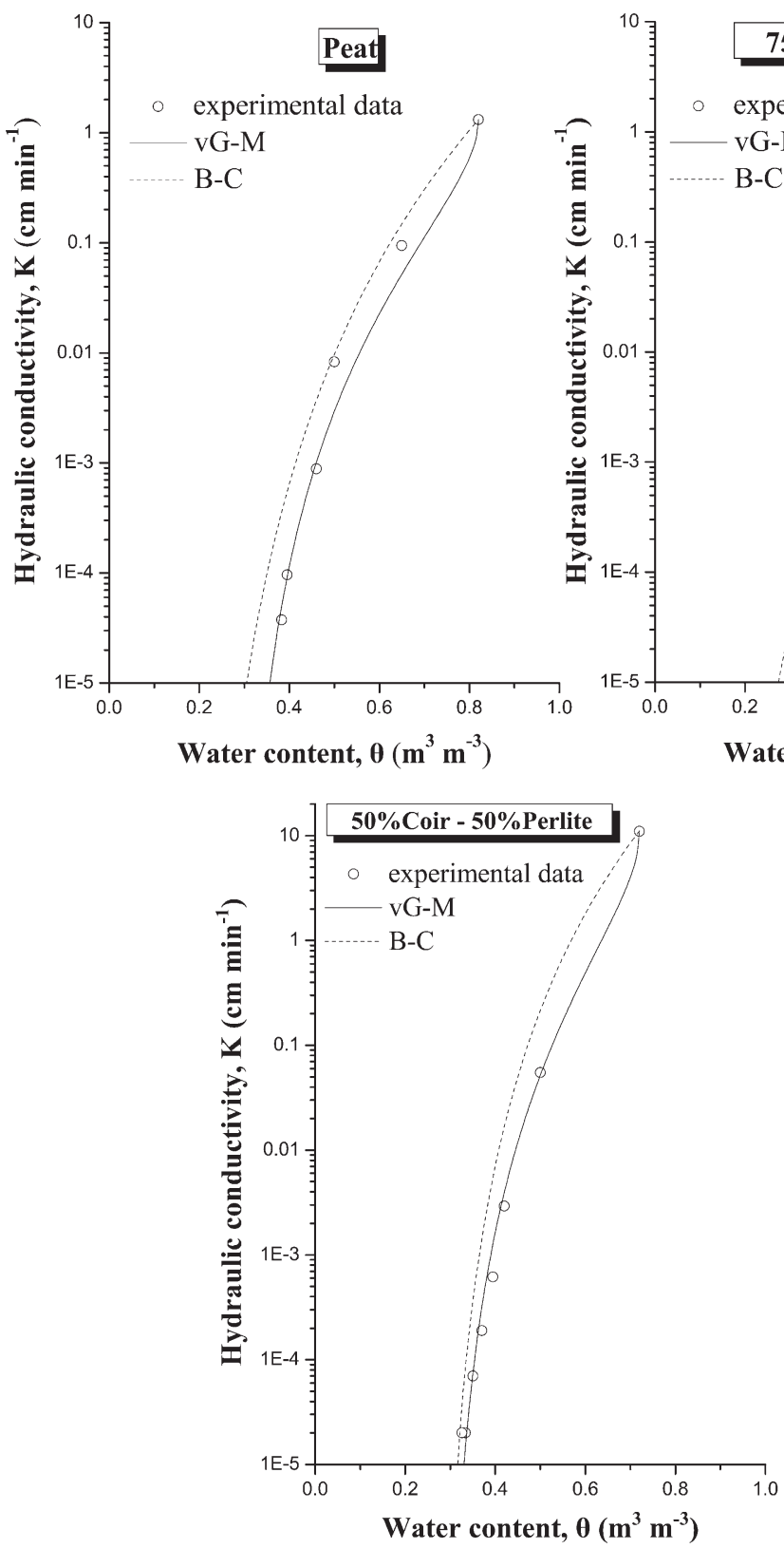
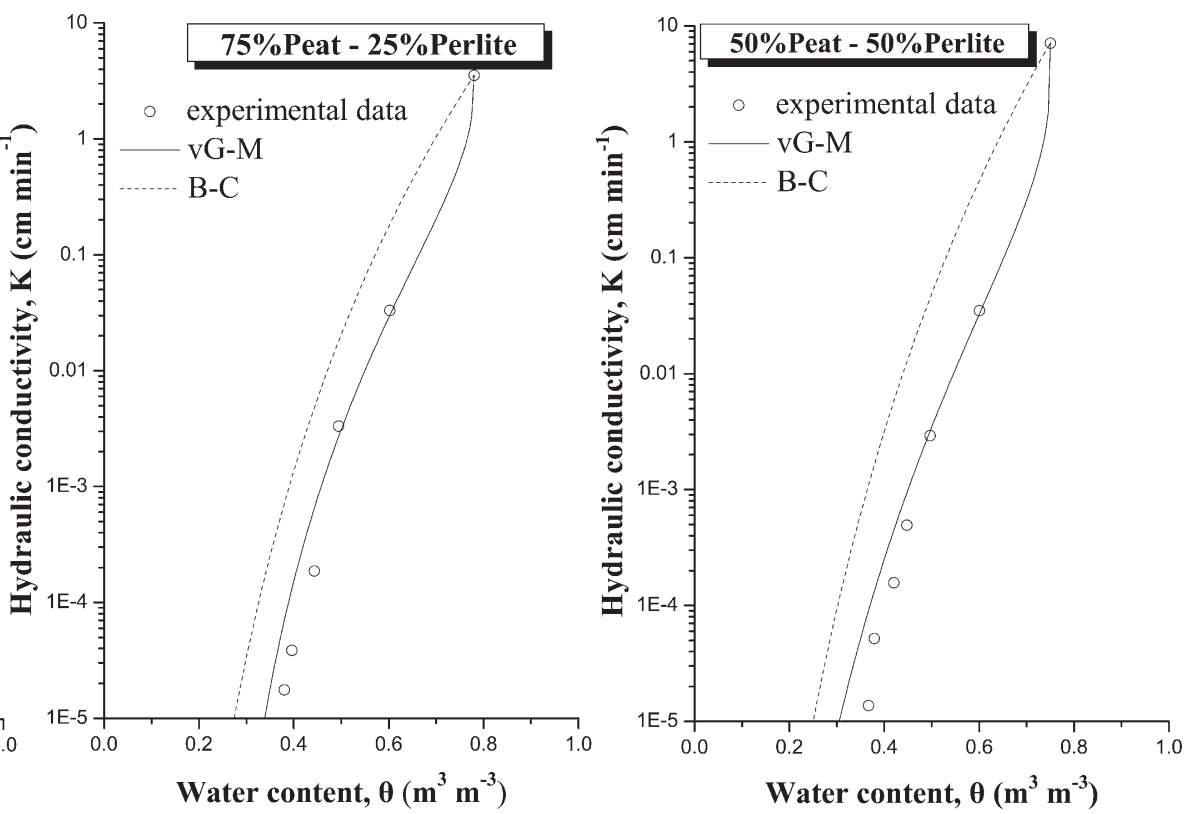

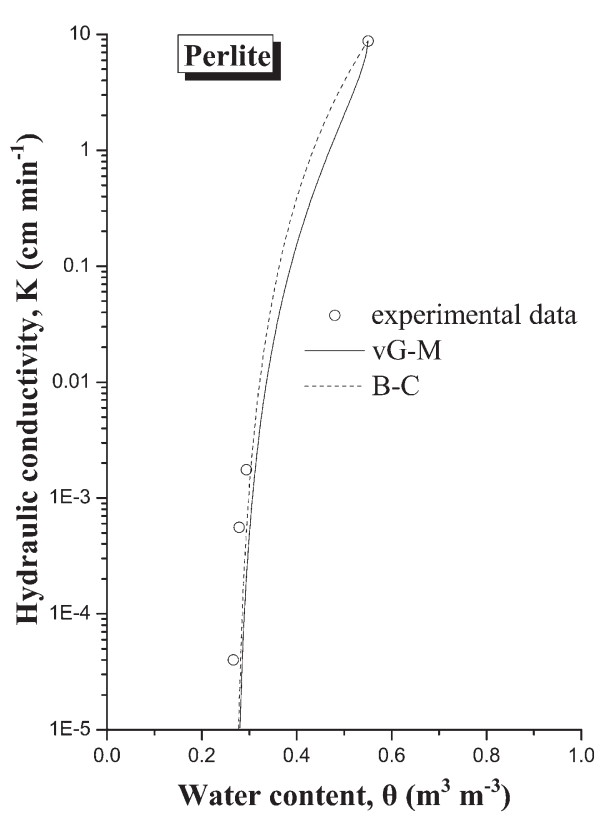

Fig. 5. Experimental and predicted by Brooks-Corey (B-C) and van Genuchten-Mualem (vG-M) models of hydraulic conductivity as a function of water content during drying for various substrates. 
data and the retention curves predicted using Brooks-Corey (B-C) and van Genuchten (vG) models is presented. A detailed description of the curve fitting parameters $h_{v}, \lambda$ and $\theta_{r}, \alpha, n$ of the B-C and $\mathrm{vG}$ water retention models, respectively, and the coefficient of determination $R^{2}$ of the fitted curves is presented in Table 3. For all substrates examined, the results indicated a high correlation between experimental and fitted data $\left(R^{2}\right.$ varying between 0.992 and 1 ). It is notable that contrary to the $\mathrm{vG}$ model, the B-C water retention model is characterized by the presence of the concept of the air-entry value. Comparison of the fitted curves with the experimental data showed the flexibility of the vG model describing the substrate water retention curve, as previously shown by Milks et al. (1989), Naasz et al. (2005), and Weiss et al. (1998).

Study of the $K(\theta)$ and $K(h)$ experimental data that are presented in Figures 3 and 4, respectively, showed that in the case of $K(\theta)$, the hysteresis phenomenon is negligible between the drying and wetting curves. For this reason, the hysteresis of $K(\theta)$ is not taken into account at different predictive hydraulic models (Mualem, 1986). On the other hand, there is hysteresis between the drying and wetting curves of $K(h)$. In the case of $50 / 50 \mathrm{coir} /$ perlite, there is poor hysteresis as compared with the peat-based substrate mixtures, which is in line with the retention curve observations.

The comparison of the $K(\theta)$ experimental data between the peat-based substrate mixtures and the coir-based substrate mixture showed that for water contents lower than $0.40 \mathrm{~m}^{3} \cdot \mathrm{m}^{-3}$, the hydraulic conductivity of the $50 / 50$ coir/perlite mixture was greater. These results are of fundamental importance as according to Darcy's law, the water flow rate of the 50/50 coir/perlite mixture has a greater capacity $(\approx 10$-fold) of replacing water losses caused by evapotranspiration in comparison with the peat-based substrate mixtures (Fig. 3). Therefore, the 50/50 coir/perlite mixture is the most suitable substrate to meet plant water demand during periods of high evapotranspiration.

Also, a sharp decrease of the unsaturated hydraulic conductivity is observed after the water content decrease and water pressure head increase (Figs. 3 and 4). Especially, the hydraulic conductivity of peat is decreased by approximately five orders of magnitude, whereas in the rest of the substrates, it is decreased by approximately six orders of magnitude for pressure heads varying from 0 to $-70 \mathrm{~cm} \mathrm{H}_{2} \mathrm{O}$. This decrease is higher during wetting. Note that this range of pressure heads in the substrates is usual among two successive irrigations. The comparison among all substrates showed that $K$ decreases at higher rates as the percentage of large pores of the substrates increases. Specifically, the rate of decrease of $K\left(K_{\text {rate }}\right)$ formed in ascending order as follows $K_{\text {rate,peat }}<K_{\text {rate, 75/ }}$ 25peat/perlite $<K_{\text {rate,50/50peat/perlite }}<K_{\text {rate,50/50coir/ }}$ perlite $<K_{\text {rate,perlite }}$.

The predicted $\mathrm{B}-\mathrm{C}$ and $\mathrm{vG}-\mathrm{M} K(\theta)$ curves, along with the experimental data, of all the substrates examined are shown in Figure 5. Table 4 provides the coefficient of determination $R^{2}$ and root mean squared errors (RMSE) between the experimental data and the $\mathrm{B}-\mathrm{C}$ and vG-M models:

$$
\begin{array}{r}
R^{2}=1-\frac{\sum\left(\log \left(K^{E}\right)-\log \left(K^{P}\right)\right)^{2}}{\sum\left(\log \left(K^{E}\right)-\frac{\sum \log \left(K^{E}\right)}{N}\right)^{2}} \\
R M S E=\sqrt{\frac{\sum\left(\log \left(K^{P}\right)-\log \left(K^{E}\right)\right)}{N}}
\end{array}
$$

where $K^{P}$ and $K^{E}$ are the predicted and experimental hydraulic conductivity, respectively, and $N$ is the number of values.

The results indicated that there is relatively good agreement between the experimental $K(\theta)$ values and the predictions obtained using the vG-M model for all the substrates used except perlite $\left(R^{2}\right.$ varying between 0.951 and 0.981). On the other hand, there is a significant deviation between the B-C $K(\theta)$ prediction and the experimental data for all the substrates examined $\left(R^{2}\right.$ varying between 0.436 and 0.872 ).

Provided that the rate of evapotranspiration is directly correlated to the hydraulic conductivity, the knowledge of $K(\theta)$ and $K(h)$, in addition to the water retention curve $\theta(h)$, is of vital importance mainly in greenhouse cultures and would contribute to alleviating water stress conditions and improving the quality of substrates.

\section{Literature Cited}

Beardsell, D.V. and D.G. Nichols. 1982. Wetting properties of dried-out nursery container media. Scientia Hort. 17:49-59.

Bilderback, T.E., W.C. Fonteno, and D.R. Johnson. 1982. Physical properties of media composed of peanut hulls, pine bark and peatmoss and their effect on azalea growth. J. Amer. Soc. Hort. Sci. 107:522-525.

Brooks, R.H. and A.T. Corey. 1964. Hydraulic properties of porous media. Hydrology Paper No.3. Civil Engineering Department, Colorado State University, Fort Collins, CO.

Burdine, N.T. 1953. Relative permeability calculations from pore-size distribution data. Petr. Trans. Am. Inst. Mining Metall. Eng. 198: 71-77.

Childs, E.C. and N. Collis-George. 1950. The permeability of porous materials. Proc. R. Soc. Lond. 201A:392-405.

Da Silva, F.F.1991. Static and Dynamic characterization of container media for irrigation management. MSc thesis, Faculty of Agriculture, Hebrew Univ. of Jerusalem, Jerusalem, Israel.

Da Silva, F.F., R. Wallach, and Y. Chen. 1993. Hydraulic properties of Sphagnum peat moss and tuff (scoria) and their potential effects on water availability. Plant Soil 154:119-126.

De Boodt, M. and O. Verdonck. 1972. The physical properties of the substrates in horticulture. Acta Hort. 26:37-44.

Fonteno, W.C., D.K. Cassel, and R.A. Larson 1981. Physical properties of three container media and their effect on Poinsettia growth. J. Amer. Soc. Hort. Sci. 106:736-741.

Heiskanen, J. 1993a. Favourable water and aeration conditions for growth media used in containerized tree seedling production: A review. Scand. J. For. Res. 8:337-358.

Heiskanen, J. 1993b. Variation in water retention characteristics of peat growth media used in tree nurseries. Silva Fenn. 27:77-97.

Heiskanen, J. 1993c. Water potential and hydraulic conductivity of peat growth media in containers during drying. Silva Fenn. 27:1-7.

Londra, P. 2001. Moisture-aeration balance of substrates as developed under different irrigation treatments. $\mathrm{PhD}$ thesis, Agricultural University of Athens, Dept. of Natural Resources Management and Agricultural Engineering, Athens, Greece.

Milks, R.R., W.C. Fonteno, and R.A. Larson. 1989. Hydrology of horticultural substrates: I. Mathematical models for moisture characteristics of horticultural container media. J. Amer. Soc. Hort. Sci. 114:48-52.

Mualem, Y. 1976. A new model for predicting the hydraulic conductivity of unsaturated porous media. Water Resour. Res. 12:513-522.

Mualem, Y. 1986. Hydraulic conductivity of unsaturated soils: Prediction and formulas, $\mathrm{p}$. 799-823. In: Klute, A. (ed.). Methods of soil analysis: Part 1, physical and mineralogical methods. American Society of Agronomy, Madison, WI.

Naasz, R., J.C. Michel, and S. Charpentier. 2005. Measuring hysteretic hydraulic properties of peat and pine bark using a transient method. Soil Sci. Soc. Amer. J. 69:13-22.

Naasz, R., J.C. Michel, and S. Charpentier. 2008. Water repellency of organic growing media related to hysteretic water retention properties. Eur. J. Soil Sci. 59:156-165.

Otten, W., P.A.C. Raats, H. Challa, and P. Kabat. 1999. Spatial and temporal dynamics of water in the root environment of potted plants on a flooded bench fertigation system. Neth. J. Agr. Sci. 47:51-65.

Poulovassilis, A. 1970. Hysteresis of pore water in granular porous bodies. Soil Sci. 109:5-12.

Poulovassilis, A., M. Polychronides, and P. Kerkides. 1988. Evaluation of various computational schemes in calculating unsaturated hydraulic conductivity. Agr. Water Manage. 13:317-327.

Puustjäarvi, V. 1977. Peat and its use in horticulture, Turveteollisuuslitto r.y. Publication 3. Liikekirjapaino, Helsinki, Finland, pp. 160.

Talsma, T. 1985. Prediction of hydraulic conductivity from soil water retention data. Soil Sci. 140:184-188

Valiantzas, J.D., P. Londra, and A. Sassalou. 2007. Explicit formulae for the soil water diffusivity using the one-step outflow technique. Soil Sci. Soc. Amer. J. 71:1685-1693.

Valiantzas, J.D. and A. Sassalou. 1991. Laboratory determination of unsaturated hydraulic conductivity using a generalized-form hydraulic model. J. Hydrol. (Amst.) 128:293-304.

van Genuchten, M.Th. 1980. A closed-form equation for predicting the hydraulic conductivity of unsaturated soils. Soil Sci. Soc. Amer. J. 44: 892-898.

Wallach, R., F.F. da Silva, and Y. Chen. 1992a. Hydraulic characteristics of Tuff (Scoria) used as a container medium. J. Amer. Hort. Sci. 117: 415-421.

Wallach, R., F.F. da Silva, and Y. Chen. 1992b. Unsaturated hydraulic characteristics of composted agricultural wastes, tuff and their mixtures. Soil Sci. 153:434-441.

Weiss, R., J. Alm, R. Laiho, and J. Laine. 1998. Modelling moisture retention in peat soils. Soil Sci. Soc. Amer. J. 62:305-313.

Youngs, E.G. 1957. Moisture profiles during vertical infiltration. Soil Sci. 84:283-290. 